\title{
Continuing Medical Education Program - a professional estimate in dentistry practice
}

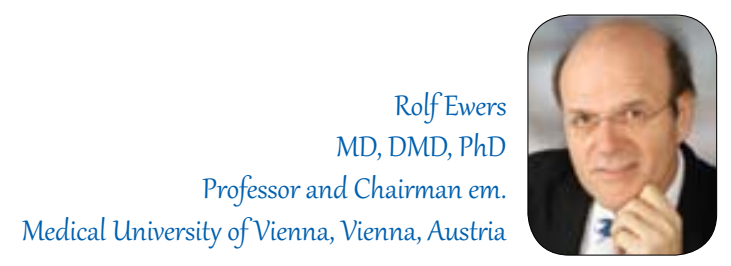

Prof. Dr. Constantinescu has asked me to serve as an Editor in Chieffor the Stomatology Edu Journal (Stoma Edu J) and consequently to be in charge with the editors for Western and Central Europe. 1 am very happy to accept this and 1 am looking forward to do so.

As Prof. Constantinescu pointed out this new dental journal will serve as a new information tool for dentists and doctors to treat patients better with the up to date knowledge which they will get in all our specialty fields by reading the peer-reviewed articles.

1 am convinced that the questionnaire at the end of each article will help the reader to really concentrate on the subject he is reading, controlling his understanding and last but not least getting points for the Continuing Medical Education Program.

1 am very happy that 1 will have the opportunity to work together with Professor ]ean-François Roulet from University of Florida and Professor Stephen F. Rosenstiel, from Ohio State University.

1 am sure that with the help and enthusiasm of Prof. Constantinescu we will achieve together with all the other editors an excellent journal for the benefit of all.

How Prof. Constantinescu says: Stoma Edu ] will be indeed a world of educational resources for each practice. 